\title{
Orthostatic changes in blood pressure and survival in elderly cardiopaths
}

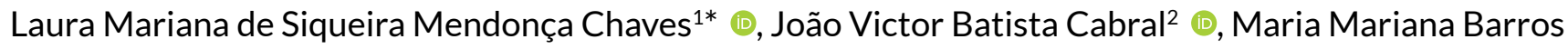

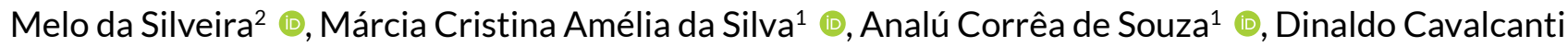

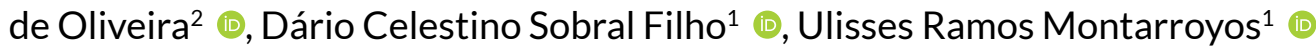

\section{SUMMARY}

OBJECTIVE: The objective of this study was to analyze the association between orthostatic changes in blood pressure and mortality in elderly cardiopath patients.

METHODS: A cohort of 455 elderly cardiopath patients, monitored at a referral outpatient cardiology clinic in Pernambuco, Brazil, from October 2015 to July 2018. The exposure groups were formed according to their orthostatic changes in blood pressure following the requirements of the Brazilian Guidelines for Hypertension.

RESULTS: Orthostatic hypotension was present in 46 patients (10.1\%), 91 had orthostatic hypertension (20\%), and 318 had no orthostatic alterations (69.9\%). There were 52 deaths during follow-up. The results demonstrated that there was no statistically significant association between orthostatic hypotension and overall mortality ( $\mathrm{HR} 1.30 ; 95 \% \mathrm{Cl} 0.53-3.14 ; \mathrm{p}=0.567)$ nor between orthostatic hypertension and overall mortality ( $\mathrm{HR} 0.95 ; 95 \% \mathrm{Cl}$ $0.65-1.39 ; p=0.34)$. Survival in relation to the exposure groups presented no statistically significant difference $(p=0.504)$.

CONCLUSION: There was a low frequency of orthostatic hypotension and a mild high frequency of orthostatic hypertension when compared with previous studies, and no association was observed with overall mortality or with the survival time of elderly patients with heart disease.

KEYWORDS: Orthostatic hypotension. Hypertension. Mortality.

\section{INTRODUCTION}

Cardiovascular aging is associated with an increased risk of diseases in elderly people, the most common of which are those arising from changes in blood pressure. Arterial stiffening, as well as vascular endothelial dysfunction, leads to an increase in systolic blood pressure and a decrease in diastolic blood pressure $^{1}$. However, autonomic dysfunction, typical of aging, makes it difficult to adapt blood pressure to orthostasis ${ }^{2}$, as well as a decrease in the number of sinus node cells and the responses mediated by beta- 1 and beta- 2 adrenergic receptors ${ }^{3}$.

In elderly people, these changes in blood pressure are associated with a progressive cardiovascular risk and target organ damage, consequently increasing morbidity and mortality ${ }^{4,5}$, since the control of blood pressure, as well as the maintenance of postural normotension, is more impaired with aging ${ }^{6}$.

Orthostatic hypotension $(\mathrm{OH})$ is characterized by a drop in systolic blood pressure of at least $20 \mathrm{mmHg}$ or diastolic blood pressure of at least $10 \mathrm{mmHg}$, when an individual changes position from lying down to sitting or standing, within an interval of three minutes between measurements, being associated or not with symptoms of cerebral hypoperfusion ${ }^{5-8}$. The prevalence of $\mathrm{OH}$ varies from 1.25 to $68 \%^{9,10}$, with a mean estimate of $30 \%{ }^{11}$. OH is associated with risk factors as diabetes mellitus ${ }^{12}$, hypertension ${ }^{13}$, Parkinson's disease ${ }^{13}$, stroke ${ }^{14}$, chronic kidney disease $(\mathrm{CKD})^{15}$, polypharmacy, and reduction in hepatic clearance, which occurs with aging ${ }^{3,16}$.

The orthostatic hypertension (OHY) is also associated with cardiovascular and overall mortality ${ }^{17-19}$. OHY is characterized by an increase of at least $20 \mathrm{mmHg}$ in blood pressure between one and two minutes after an individual has stood up ${ }^{4}$.

Thus, the aim of this study was to estimate the association between orthostatic changes (OC) in blood pressure and overall mortality in elderly cardiopath patients.

\section{METHODS}

This was a cohort study with a comparison of groups. The sample consisted of 455 elderly patients aged 65 and over, diagnosed with cardiovascular disease, selected consecutively, and treated at the general cardiology outpatient clinic of a referral

\footnotetext{
${ }^{1}$ Universidade de Pernambuco, Postgraduate Program in Health Sciences - Recife (PE), Brazil.

¿Universidade de Pernambuco, Postgraduate Program in Therapeutic Innovation - Recife (PE), Brazil.

${ }^{*}$ Corresponding author: laurinhaupe@yahoo.com.br

Conflicts of interest: the authors declare there is no conflicts of interest. Funding: none.

Received on Aug 07, 2021. Accepted on Nov 01, 2021.
} 
hospital in Pernambuco, Brazil, from October to November 2015 and monitored until July 31, 2018.

Participants were examined on the day of inclusion in the study with a physical examination performed by measuring the blood pressure while lying down, sitting, and standing, with an interval of three minutes between each, together and an interview to collect biological characteristics, life habits, comorbidities, and use of medications. The search for information on deaths was conducted via the Mortality Information System (SIM) throughout the whole study period.

Patients were excluded from the study if they were prevented, for any reason, from assuming the orthostatic position without the help of third parties for five minutes, together with those who had taken cardiovascular medication up to two hours prior to measuring the blood pressure, or presented with uncorrected severe bilateral hearing loss, severe cognitive impairment, and without a legal guardian.

The exposure groups were formed according to their OC in blood pressure following the requirements of the Brazilian Guidelines for Hypertension. $\mathrm{OH}$ was defined by a drop in the blood pressure of at least $20 \mathrm{mmHg}$ in systolic pressure or at least $10 \mathrm{mmHg}$ in diastolic pressure after standing for one, three, or five minutes. OHY was defined by an increase in blood pressure of at least $20 \mathrm{mmHg}$ after standing up for two minutes ${ }^{20}$.

A descriptive analysis of the characterization and description of the participants was conducted regarding the biological variables, comorbidities, and the medications being taken. The densities of death incidence in 100 person-years and their confidence intervals were estimated according to the condition of the $\mathrm{OH}$ and OHY. The associations were analyzed independently. The survival probability was calculated and represented by the Kaplan-Meier curve and the differences between the survival functions were tested according to the condition of the $\mathrm{OH}$ and $\mathrm{OHY}$ by the Log-Rank test.

In the multivariate analysis, possible confounding factors were analyzed by comparing the groups of patients according to the condition of the $\mathrm{OH}$ and $\mathrm{OHY}$, with the biological variables, comorbidities, and medications being taken. The assessment was performed using the chi-squared, Fisher's exact, or Pearson test, and ANOVA was used to compare the mean values. The adjusted measures were estimated by Cox regression analysis. The inclusion criterion for selecting the confounding variables in the adjustment of the hazard ratio (HR) was a significance of up to $20 \%$ in the analysis of the comparison of groups according to exposure $(\mathrm{p}<0.2)$. The level of significance adopted in the analysis of associations was $5 \%(\mathrm{p}<0.05)$.
All patients selected for the study signed the Informed Consent Term and the study is in accordance with that described in resolution no. 466/2012, in addition was approved by the Research in Ethics Committee of the Hospital Complex HUOC/ PROCAPE (CAAE: 84801918.4.0000.5192).

\section{RESULTS}

A total of 455 patients participated in the study, of which 46 were diagnosed with $\mathrm{OH}(10.1 \%)$, 91 with $\mathrm{OHY}(20 \%)$, and 318 presented with no OC (69.9\%). Table 1 describes the biological, lifestyle, and clinical characteristics of the study population. The mean age did not differ between groups ( $72.7 \pm 6.4$ years). There was a higher frequency of females, with no difference between the exposure groups. With regard to lifestyle, there was no predominance of either alcohol or illicit drugs use between the groups.

Among the most frequent, arterial hypertension was reported by $94 \%$ of patients, and was predominant in all groups. More than half (51\%) presented with coronary artery disease (CAD), 53\% presented dyslipidemia (DLP), and 35.8\% diabetes. With regard to the use of medications, polypharmacy was present in $23.2 \%$ of patients (taking four or more medications per day). Almost all patients used antihypertensive drugs (99.87\%), where the most commonly used were betablockers (72\%) and diuretics (58.9\%) (Table 1).

A total of 52 deaths were registered during the 36-month follow-up period, average follow-up time was 24.7 months, with an average of 6 deaths/year for every 100 patients. According to Figure 1, the cumulative probability of death in the first 12 months of follow-up was $4.8 \%$ and in 24 months, $10.7 \%$. Survival in relation to the exposure groups presented no statistically significant difference $(\mathrm{p}=0.504)$.

The mortality rate per year related to the $\mathrm{OH}$ group was 6.8 and in patients with OHY the rate was 7.9 deaths per 100 person-years. After estimating the risk of death adjusted by confounding factors, the HR was neither statistically significant for the $\mathrm{OH}$ group nor the $\mathrm{OHY}$ group (Figure 2).

Diseases of the cardiocirculatory system were responsible for the highest number of deaths in the group with no OC $(54.8 \%)$ and in the group with $\mathrm{OH}(42.9 \%)$. The deaths of patients in the OHY group were attributed to respiratory system diseases $(42.9 \%)$.

\section{DISCUSSION}

In the present study, in a sample of 455 elderly cardiopath patients monitored on an outpatient basis, aged between 66 and 
Table 1. Biological, lifestyle, and clinical characteristics of the elderly patients according to the classification of orthostatic changes.

\begin{tabular}{|c|c|c|c|c|}
\hline Characteristics & $\begin{array}{c}\text { No OC } \\
(n=318) \\
(\%)\end{array}$ & $\begin{array}{c}\mathrm{OH} \\
(\mathrm{n}=46) \\
(\%)\end{array}$ & $\begin{array}{c}\text { ОНY } \\
(n=91) \\
(\%)\end{array}$ & p-value \\
\hline Age (mean $\pm S D)$ & $72.5 \pm 5.9$ & $72.4 \pm 8.2$ & $73.7 \pm 7.1$ & 0.265 \\
\hline \multicolumn{5}{|l|}{ Sex } \\
\hline Male & $150(47.2)$ & 18 (39.1) & $37(40.7)$ & 0.380 \\
\hline Female & $168(52.8)$ & 28 (60.9) & 54 (59.3) & \\
\hline \multicolumn{5}{|l|}{ Alcohol } \\
\hline Yes & $34(10.7)$ & $3(6.5)$ & $8(8.8)$ & 0.626 \\
\hline No & 284 (89.3) & 43 (93.5) & $83(91.2)$ & \\
\hline \multicolumn{5}{|l|}{ Illicit drug use } \\
\hline Yes & $3(0.9)$ & $\mathrm{O}(0)$ & $1(1.1)$ & 0.789 \\
\hline No & 315 (99.1) & $46(100)$ & $90(98.9)$ & \\
\hline \multicolumn{5}{|c|}{ Hospitalization in the last 12 months } \\
\hline Yes & $92(29.2)$ & $10(21.7)$ & $22(24.4)$ & 0.439 \\
\hline No & $223(70.8)$ & $36(78.2)$ & $68(75.6)$ & \\
\hline \multicolumn{5}{|l|}{ Comorbidities } \\
\hline Atrial fibrillation & $41(12.9)$ & $7(16.2)$ & $18(20.0)$ & 0.235 \\
\hline Arterial hypertension & $297(93.4)$ & 45 (97.8) & 84 (92.3) & 0.438 \\
\hline Diabetes mellitus & $107(33.6)$ & $19(41.3)$ & 36 (39.5) & 0.406 \\
\hline Dyslipidemia & $175(55)$ & $18(39.1)$ & $47(51.6)$ & 0.127 \\
\hline $\mathrm{CAD}^{*}$ & $179(56.3)$ & $19(41.3)$ & $45(49.4)$ & 0.114 \\
\hline CKD* & $28(8.8)$ & $6(13)$ & $6(6.6)$ & 0.453 \\
\hline Hypothyroidism & $15(4.7)$ & $3(6.5)$ & $6(6.6)$ & 0.720 \\
\hline Parkinson's disease & $8(2.5)$ & $1(2.2)$ & $1(1.1)$ & 0.719 \\
\hline Stroke & $43(13.5)$ & $4(8.7)$ & $8(8.8)$ & 0.360 \\
\hline Cardiac insufficiency & $117(36.8)$ & $13(28.3)$ & $32(35.2)$ & 0.526 \\
\hline Previous depression & $51(16)$ & $8(17.4)$ & $17(18.7)$ & 0.830 \\
\hline Anemia & $21(6.6)$ & $5(10.9)$ & $11(12.1)$ & 0.186 \\
\hline \multicolumn{5}{|l|}{ Medication use } \\
\hline Antihypertensive drugs & $318(100)$ & $46(100)$ & $90(98.9)$ & 0.135 \\
\hline Vasodilators & $28(8.9)$ & $6(13.6)$ & $10(11)$ & 0.550 \\
\hline Betablockers & $231(72.6)$ & $30(65.2)$ & $67(73.6)$ & 0.539 \\
\hline Calcium blockers & 99 (31.1) & $22(47.8)$ & $20(22)$ & 0.008 \\
\hline ACEI* or Ara II* $^{*}$ & $140(44)$ & $22(47.9)$ & $36(39.6)$ & 0.619 \\
\hline Diuretics & $192(60.4)$ & $24(52.2)$ & $52(57.1)$ & 0.532 \\
\hline Antidepressants & $21(6.6)$ & $1(2.2)$ & $8(8.8)$ & 0.337 \\
\hline Sedatives & $49(15.5)$ & 5 (10.9) & 19 (20.9) & 0.277 \\
\hline Nitrates & $72(22.6)$ & $7(15.2)$ & $20(22)$ & 0.521 \\
\hline \multicolumn{5}{|c|}{ Number of classes of medication } \\
\hline One & $25(7.9)$ & $4(8.7)$ & $14(15.4)$ & 0.535 \\
\hline Two & $91(28.8)$ & $13(28.3)$ & $26(28.6)$ & \\
\hline Three & $126(39.9)$ & $17(37)$ & $31(34.1)$ & \\
\hline Four or more & $74(23.4)$ & $12(26.1)$ & $20(22)$ & \\
\hline
\end{tabular}

OC: orthostatic changes; $\mathrm{OH}$ : orthostatic hypotension; OHY: orthostatic hypertension; CAD: coronary artery disease; CKD: chronic kidney disease; ACEI: angiotensin-converting enzyme inhibitor; ARA II: angiotensin II receptor antagonists.

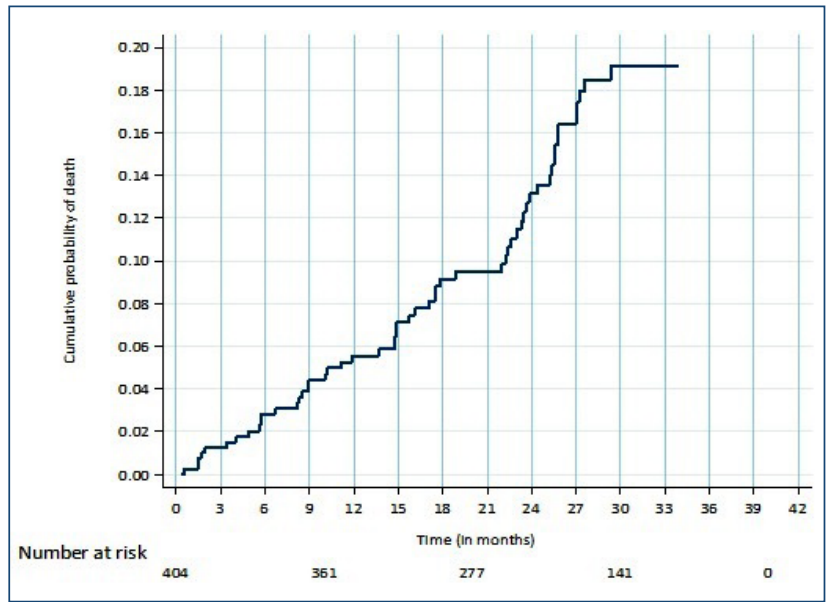

Figure 1. Overall survival curve.

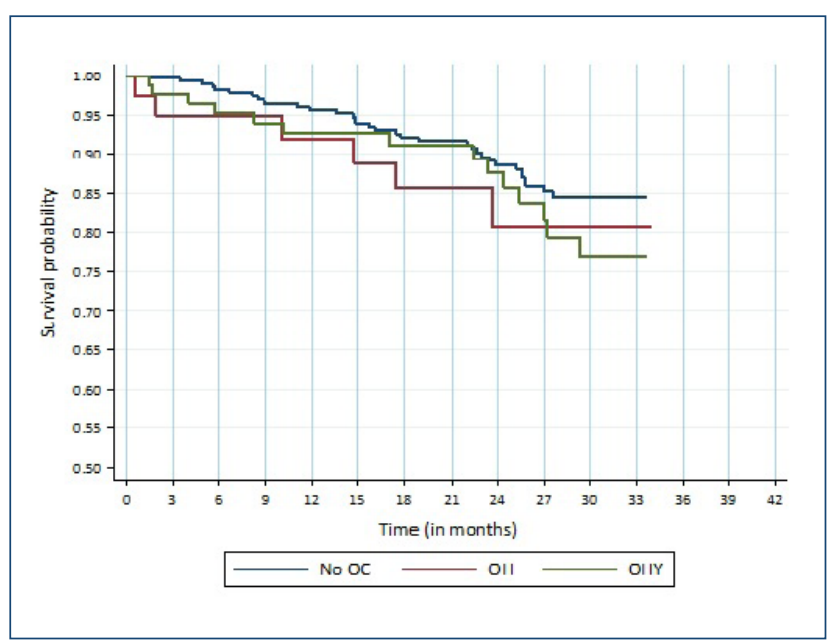

Figure 2. Overall survival related to classification of orthostatic changes.

78 years, the prevalence of $\mathrm{OH}$ was $10.1 \%$, similar to studies by Ong et al. $(2017)^{21}$ and Freud et al. $(2018)^{17}$, which demonstrated a prevalence of 7.8 and $18 \%$, respectively. Both studies assessed $\mathrm{OH}$ in elderly people in the same age group as the present study, also monitored on an outpatient basis.

With regard to $\mathrm{OH}$ and overall mortality, our results have demonstrated that there was no statistically significant association (HR 1.30; 95\%CI 0.53-3.14; $\mathrm{p}=0.567$ ), thereby corroborating the findings by Szyndler et al. ${ }^{18}$, who assessed the impact of $\mathrm{OH}$ on cardiovascular and noncardiovascular mortality in 209 octogenarians over a period of 24 months, and also reported no association with mortality. In the studies by Veronese et al. ${ }^{19}$ and Freud et al. ${ }^{17}, \mathrm{OH}$ was associated with overall mortality in the univariate analysis. However, after adjusting the multivariate analysis, this association was no longer significant. 
According to Freud et al. ${ }^{17}$, both in the group of patients aged 75 years and under and in the group aged 75 years and over (which included fragile older adults), no association was reported between $\mathrm{OH}$ and overall mortality in the multivariate analysis. A similar result was observed in the study by Veronese et al. ${ }^{19}$, who monitored 2,786 older adults for four years, with the same mean age and after adjusting for confounding factors, the association of $\mathrm{OH}$ was no longer significant for overall mortality.

However, $\mathrm{OH}$ was a risk factor for death related to noncardiovascular diseases. The aforementioned studies have a larger sample size, a longer follow-up time, and a higher prevalence of older people with $\mathrm{OH}$, reinforcing the evidence from the present study of no association between $\mathrm{OH}$ and overall mortality.

In our sample, OHY was observed in $20 \%$ of the older patients, an above-average prevalence for large studies such as those by Bursztyn et al..$^{22}$ and Veronese et al. ${ }^{19}$, who assessed elderly patients with OHY monitored on an outpatient basis. The study by Bursztyn et al. ${ }^{22}$, a cohort that monitored 1,441 elderly patients, who aged 85-95, for 10 years, reported a prevalence of OHY of only 3 to $4 \%$.

In the present study, there was no increase in OHY-related mortality (HR 0.95; 95\%CI 0.65-1.39; $\mathrm{p}=0.34$ ), a result similar to that reported by Weiss et al. ${ }^{23}$, in a prospective cohort of 474 hospitalized older patients, aged between 75 and 87 years, who assessed the association between OHY and mortality.

It should be noted that there are divergences in the literature regarding $\mathrm{OHY}$ and its association with mortality. In the study by Veronese et al. ${ }^{19}$, in relation to OHY, there was an association both with overall mortality (HR 1.23; 95\% CI 1.02-1.39; $\mathrm{p}=0.03)$ and with diseases of the cardiovascular system (HR 1.41; 95\%CI 1.08-1.74; $\mathrm{p}=0.02$ ) after adjusting for confounding factors.

Studies related to the association of mortality with $\mathrm{OHY}$ have different characteristics, which may explain the different

\section{REFERENCES}

1. Falcão CA. Cardiologia: Diagnóstico e tratamento. Rio de Janeiro: Med Book; 2017.

2. Guyton AC, Hall JE. Nervous regulation of the circulation, and rapid control of arterial pressure in Guyton\& Hall - textbook of medical physiology. Philadelphia: Elsevier Saunders; 2011.

3. Cleophas TJ, van Marum R. Age-related decline in autonomic control of blood pressure: implications for the pharmacological management of hypertension in the elderly. Drugs Aging. 2003;20(5):313-9. https://doi.org/10.2165/00002512200320050-00001

4. Kario K. Orthostatic hypertension: a measure of blood pressure variation for predicting cardiovascular risk. Circ J. 2009;73(6):1002-7. https://doi.org/10.1253/circj.cj-09-0286 results related to the association with mortality. In the present study, the risk of death in patients with $\mathrm{OHY}$ was 1.48 (95\%CI $0.8-2.79$ ), with a statistical significance of $20 \%$ and a study power equal to $85 \%$. Only 14 deaths were observed in this group, which may have influenced the instability of the risk measure, and consequently a greater inaccuracy of the risk measure (HR). Thus, the study indicates a risk hypothesis, although a longer follow-up period would be necessary, with a greater number of events observed for the cohort of patients with OHY.

\section{CONCLUSIONS}

It is concluded that there was a low frequency of $\mathrm{OH}$ and a slightly high frequency of OHY and that they were not associated with overall mortality and presented no influence over the survival of the elderly cardiopath patients.

\section{ACKNOWLEDGMENTS}

This study was conducted with the support of the Coordination for the Improvement of Higher Education Personnel - Brazil (CAPES) - Financing Code 001.

\section{AUTHORS' CONTRIBUTIONS}

LMSMC: Conceptualization, Data curation, Formal Analysis, Writing - original draft. JVBC: Data curation, Writing - original draft. MMBMS: Data curation, Writing - original draft. MCAS: Data curation, Writing - original draft. ACS: Data curation, Writing - original draft. DCO: Writing - original draft, Writing - review \& editing. DCSF: Writing - original draft, Writing - review \& editing. URM: Writing - original draft, Writing - review \& editing.

5. Kario K, Eguchi K, Hoshide S, Hoshide Y, Umeda Y, Mitsuhashi T,etal. U-curve relationship between orthostatic blood pressure change and silent cerebrovascular disease in elderly hypertensives: orthostatic hypertension as a new cardiovascular risk factor. J Am Coll Cardiol. 2002;40(1):133-41.https://doi.org/10.1016/s0735-1097(02)01923-x

6. Naschitz JE, Rosner I. Orthostatic hypotension: framework of the syndrome. Postgrad Med J. 83(983):568-74. https://doi. org/10.1136/pgmj.2007.058198

7. Mader SL. Identification and management of orthostatic hypotension in older and medically complex patients. Expert Rev Cardiovasc Ther. 2012;10(3):387-95. https://doi.org/10.1586/ erc.12.11

8. Gibbons $\mathrm{CH}$, Freeman R. Orthostatic dyspnea: a neglected symptom of orthostatic hypotension. Clin Auton Res. 2005:15(1):40-4. https://doi.org/10.1007/s10286-005-0227-1 
9. Baliga R, Prabhu G. Orthostatic hypotension in healthy elderly: Is it a myth? N Am J Med Sci. 2010;2(9):416-8. https://doi.org/10.4297/ najms.2010.2416

10. Weiss A, Grossman E, Beloosesky Y, Grinblat J. Orthostatic hypotension in acute geriatric ward: is it a consistent finding? Arch Intern Med. 2002;162(20):2369-74. https://doi.org/10.1001/ archinte.162.20.2369

11. Lipp A, Sandroni P, Ahlskog JE, Fealey RD, Kimpinski K, lodice V, et al. Prospective differentiation of multiple system atrophy from Parkinson disease, with and without autonomic failure. Arch Neurol. 2009;66(6):742-50. https://doi.org/10.1001/archneurol.2009.71

12. Wu JS, Yang YC, Lu FH, Wu CH, Wang RH, Chang CJ. Populationbased study on the prevalence and risk factors of orthostatic hypotension in subjects with pre-diabetes and diabetes. Diabetes Care. 2009;32(1):69-74. https://doi.org/10.2337/dc08-1389

13. Bouhaddi M, Vuillier F, Fortrat JO, CappelleS, Henriet MT, Rumbach L, et al. Impaired cardiovascular autonomic control in newly and long-term-treated patients with Parkinson's disease: involvement of L-dopa therapy. Auton Neurosci. 2004;116(1-2):30-8. https:// doi.org/10.1016/j.autneu.2004.06.009

14. Kong KH, Chuo AM. Incidence and outcome of orthostatic hypotension in stroke patients undergoing rehabilitation. Arch Phys Med Rehabil. 2003;84(4):559-62. https://doi.org/10.1053/ apmr.2003.50040

15. DiLeo R, VitaG,MessinaC,SavicaV.Autonomicfunctioninelderlyuremics studied by spectral analysis of heart rate. Kidney Int. 2005;67(4):1521-5. https://doi.org/10.1111/j.1523-1755.2005.00231.x

16. Mehagnoul-Schipper DJ, ColierWN, Hoefnagels WH, VerheugtFW, Jansen RW. Effects of furosemide versus captopril on postprandial and orthostatic blood pressure and on cerebral oxygenation in patients > or $=70$ years of age with heartfailure. Am J Cardiol. 2002;90(6):596600. https://doi.org/10.1016/s0002-9149(02)02562-6
17. Freud T, Punchik B, Kagan E, Barzak A, Press Y. Orthostatic hypotension and overall mortality in 1050 older patients of the outpatient comprehensive geriatric assessment unit. Geriatr Gerontol Int. 2018;18(7):1009-17. https://doi.org/10.1111/ ggi.13291

18. Szyndler A, Dereziński T, Wolf J, Narkiewicz K. Impact of orthostatic hypotension and antihypertensive drug treatment on total and cardiovascular mortality in a very elderly community-dwelling population. J Hypertens. 2019;37(2):331-8. https://doi.org/10.1097/ HJH.0000000000001878

19. Veronese N, De Rui M, Bolzetta F, Zambon S, Corti MC, Baggio G et al. Orthostatic changes in blood pressure and mortality in the elderly: the Pro.V.A study. Am J Hypertens. 2015;28(10):1248-56. https://doi.org/10.1093/ajh/hpv022

20. Malachias MVB, Souza WKSB, Plavnik FL, Rodrigues CIS, Brandão AA, Neves MFT, et al. VII Diretriz de Hipertensão. Diretriz Brasileira de Cardiologia. Arq Bras Cardiol. 2016;107(Suppl 3):1-91. https:// doi.org/10.5935/abc.20160152

21. Ong HL, Abdin E, Seow E, Pang S, Sagayadevan V, Chang S, et al. Prevalence and associative factors of orthostatic hypotension in older adults: results from the Well-being of the Singapore Elderly (WiSE) study. Arch Gerontol Geriatr. 2017;72:146-52. https://doi. org/10.1016/j.archger.2017.06.004

22. Bursztyn M, Jacobs JM, Hammerman-Rozenberg A, Stessman J. Prevalence of orthostatic hypertension in the very elderly and its relationship to all-cause mortality. J Hypertens. 2016;34(10):2053-8. https://doi.org/10.1097/ HJH.0000000000001044

23. Weiss A, Beloosesky Y, Grossman A, Shlesinger A, Koren-Morag $\mathrm{N}$, Grossman E. The association between orthostatic hypertension and all-cause mortality in hospitalized elderly persons. J Geriatr Cardiol. 2016;13(3):239-43. https://doi.org/10.11909/j.issn.1671 5411.2016.03.004 